\title{
TECHNIQUE AND RESULTS WITH THE ACRYLIC FEMORAL HEAD PROSTHESIS*
}

\author{
Robert and Jean Judet, Paris, France
}

The general idea which has led to our operation for arthroplasty of the hip is contained in the French word " resection-reconstruction." Resection of part of the femoral head is necessary. Sixteen years ago we used to treat osteoarthritis of the hip by Whitman's operation, and like other surgeons we observed the immediate relief of pain that followed removal of the head, where in our opinion the most important lesions of osteoarthritis of the hip are to be found. Reconstruction of the head is also necessary. The late results in patients operated upon by the Whitman technique without such reconstruction are almost always the same: there is inability to bear weight fully and, after a few months, pain and stiffness if the stump of the neck is large, or unsteadiness if it is short.

Our experiments with the use of methyl-polymethacrylate showed that it was suitable for use as a prosthetic material. After some trials we designed a head of simple shape which has not been changed from the time of our fifteenth case. In the first hundred cases, however, we had fourteen instances of fracture of the acrylic stem. This has not occurred since we increased the strength of the stem by moulding the original block of acrylic resin round a bar of stainless steel. Insertion of a similar bar of metal at a later stage by boring the stem does not give such efficient reinforcement.

\section{TECHNIQUE}

The essential steps in the technique of operation have already been described (Judet and Judet 1950). Here we shall stress only a few particular points.

Incision-We use Hueter's short anterior incision. Access to the hip joint is simple, quick and free from haemorrhage. It gives sufficient exposure without damaging the muscles, an important point with regard to the final result. With care the lateral cutaneous nerve of the thigh can be avoided. Other incisions such as those of Smith-Petersen, Ollier, Langenbeck, Gibson and others give a larger exposure but usually this is not required.

The capsule--In our first hundred cases we sutured the capsule with a cross-stitch at the end of the operation. In another hundred cases it was freely resected. The results were similar. Now we resect only a small medial area of the capsule over the head of the femur in order to minimise the risk of impairing the blood supply of the head and neck.

The track for the stem-In our earliest cases we drove the reamer more vertically in order to have the head of the prosthesis seated in a position of coxa valga. This was a mistake and we now consider that coxa valga of the prosthesis often causes pain. The coxa vara position is no better. The correct position for the stem is along the true axis of the neck. This position can be obtained by keeping the reamer parallel with the anterior, posterior and inferior cortical surfaces of the neck. The square end of the stem should perforate the subtrochanteric cortex, but it should not protrude more than half a centimetre.

The acetabulum -We have always considered that resection of part of the head removed most of the pain and that remodelling of the acetabulum was necessary only to obtain a close fit of the prosthesis. The numbers of our cases with and without acetabuloplasty are the same. There is no significant difference between the results. When acetabuloplasty has been done it has been for mechanical reasons; we therefore regard it as a mechanical requirement rather

* Paper read at the Annual Meeting of the British Orthopaedic Association in Edinburgh, October 1951. 
than as a form of treatment. It is always necessary, however, to remove osteophytes from the acetabular rim, especially the superior ones.

Post-operative treatment--Immediately after the operation a below-knee plaster is applied with a transierse piece of wood behind the heel to maintain some medial rotation of

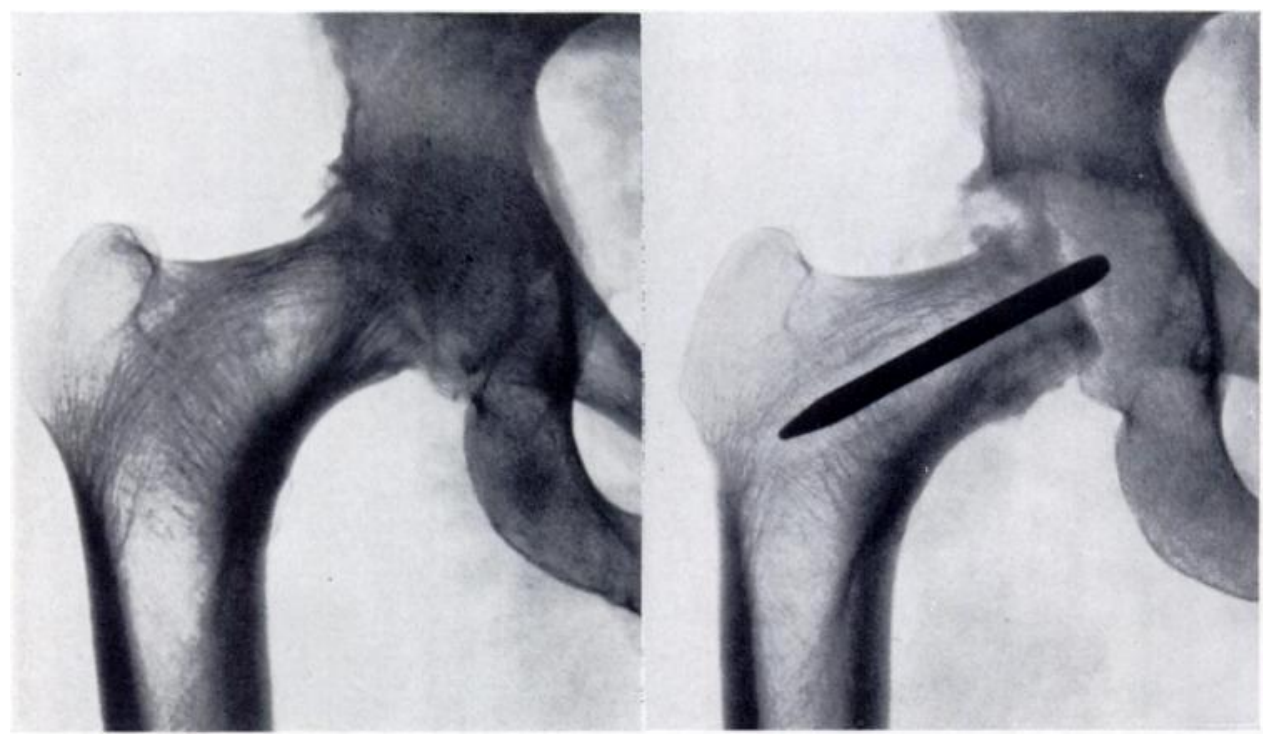

$$
\text { Fili. } 1
$$

Fig. 2

Finure 1 The radiograph of a patient with osteoarthritis of the hip before operation at the Roval National (Orthopaedic Hospital in October 1951. Figure 2- Note the limited amount of hearl removed, the axial position of the stem and the perforation of the lateral cortex. The acetabulum was not remouldecl.

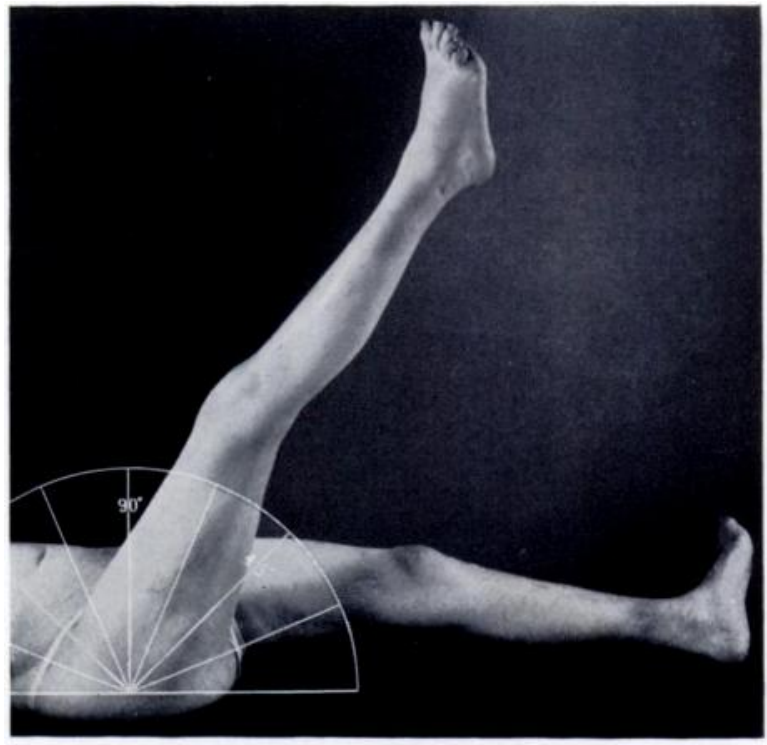

FIG. 3

To show the range of straight-ley raising three months after operation.

the lower limb. The limb is held slightly abducted. Eight day's later movement of the hip is begun in the suspension apparatus. Twelve days after the operation the plaster is removed and the patient begins to walk. Weight-bearing without crutches but with a 
stick and the help of a physiotherapist is encouraged. The patient is often fit to return to work two or three months after the operation. Gymnastics should be continued for a year or more after the operation because the result slowly improves for a long time. (This regime of after-treatment does not apply to cases of old congenital dislocation of the hip, which are discussed at the end of this paper.)

\section{CLINICAL MATERIAL}

This study is based upon four hundred patients operated upon between one and five years ago either by my brother or by myself. About two hundred more recent cases have been excluded.

Method of assessment of results-We use a numerical evaluation with "points" for pain, movement and gait. For the estimation of movement we measure the range in all directions from the anatomical position, which is counted as 0 degrees. An example is given in Table I. When there is fixed deformity this is recorded with a negative number. The movement is divided into six grades, as shown in Table II.

TABLE I

Specinex Case showing how the Range of Movement is Recorded

\begin{tabular}{|c|c|c|c|c|c|c|c|}
\hline & Flexion & Extension & Abduction & Adduction & $\begin{array}{l}\text { Lateral } \\
\text { rotation }\end{array}$ & $\begin{array}{l}\text { Medial } \\
\text { rotation }\end{array}$ & Total \\
\hline Right & 80 & -30 & -5 & 20 & 60 & 0 & $\begin{array}{c}125 \\
\text { (Grade 4) }\end{array}$ \\
\hline Left & 130 & 11) & 30 & 20 & 40 & 20 & $\begin{array}{c}250 \\
\text { (Crade 6) }\end{array}$ \\
\hline
\end{tabular}

TABLE II

Grading of Disability According to Pain, Movenent ani) (apacity for WALKING

\begin{tabular}{|c|c|c|c|}
\hline & PAIN & MOVEMEXT & WALKING \\
\hline 1 & Severe-loss of sleep & Fixed in bad position & Impossible or almost so \\
\hline 2 & $\begin{array}{l}\text { Severe when walking- } \\
\text { unabie to work }\end{array}$ & Fixed in good position & Short distances only \\
\hline 3 & $\begin{array}{l}\text { Nicderate- } \\
\text { able to do light work }\end{array}$ & $0^{c}-70$ & $\begin{array}{l}\text { Restricted, } e . ., \text { an hour } \\
\text { with one stick }\end{array}$ \\
\hline 4 & $\begin{array}{l}\text { Pain after effort, } \\
\text { relieved by rest }\end{array}$ & $70^{\circ}-140^{\circ}$ & $\begin{array}{l}\text { Long distances with a } \\
\text { stick but short without }\end{array}$ \\
\hline 5 & $\begin{array}{l}\text { Slight and intermittent- } \\
\text { able to do full work }\end{array}$ & $140-200^{\circ}$ & No stick, but limping \\
\hline 6 & Absent & $200^{\circ}-300$ & Normal \\
\hline
\end{tabular}

The degree of pain and the ability to walk are also divided into six grades (Table II). A patient may therefore be graded by three numbers-for example: pain 3 ; movement 4 ; gait 3. These numbers 343 express accurately the state of the hip. The sum of the three numbers gives a total figure which can easily be compared with another figure obtained by examination some time after the operation. We use the terms "starting rate" (SR) for the number before operation and "final rate" (FR) for the number at the last examination. The "amelioration rate" (AR) is the difference between these two. We regard the result

vOL. 34 B, NO. 2, MAY 1952 
as bad when the amelioration rate is between 0 and 3 , poor between 3 and 6 , good between 6 and 9, and excellent when it is above 9. The great advantages of this method of grading the condition of the joint are that self-complacency is almost eliminated and that different surgeons may compare their results.

\section{COMPLICATIONS}

Mortality-Seven patients died in the first month after operation, a mortality rate of 1.8 per cent. The causes of death were the usual ones found in any series of elderly patients.

Haematoma formation-In most cases this is associated with slight infection proved by the laboratory findings. A haematoma must be emptied by aspiration, several times if necessary, because it can be the starting point of a serious infection.

Wound infection-Fifteen patients (3.8 per cent) developed an infection. In seven we had to remove the prosthesis and put the stump of the neck in the acetabulum as in Whitman's operation. The result in each case was bad. In the other eight cases we obtained healing but with poor function.

The prevention of infection remains a problem, but during the last year we have successfully treated four acute cases by the following method. The incision is opened freely down to the joint. All blood clot and pus are removed by lavage with saline solution or ether without dislocating the joint. The wound is closed round two or three Carrel drains. During the next five days injections are given into the tubes with a solution of penicillin and streptomycin at the rate of one or two million units and one gramme per day. At the same time general treatment is given with antibiotics according to the laboratory findings. On the sixth day the tubes are themselves replaced by needles which are removed a few days later.

Persistent pain-Persistent pain may result from the following causes: Poor selection of cases-Lack of care in the selection of patients who are to be operated upon can be a cause of failure. We have never refused a patient because of severe changes in the hip itself, but we have done so for general reasons, such as senility as distinct from great age, obesity with circulatory changes in the legs, certain general diseases and above all lack of sufficient determination to co-operate. Every time we have neglected these general contra-indications the result has been either poor or bad. The only case for which we make an exception is that in which the patient has pain at night sufficient to make life miserable, but we prepare such patients as long as necessary in order to improve their condition before operation. Apart from the cases mentioned above the most important reason for bad results is faulty insertion of the prosthesis.

Lack of congruity-The head of the prosthesis may not fit well into the acetabulum. In our first cases we purposely made a socket too large for the head. This is a mistake because the area of pressure on the acetabulum is then too small; the local pressure is therefore too high and produces bone sclerosis of the roof of the acetabulum, leading to pain. On the contrary the head must fit the socket as exactly as possible. Sometimes audible creaking is a proof of good fitting, and such creaking may persist for several months after the operation.

Too lateral a position of the head in the acetabulum is also bad. This occurs when the roof of the acetabulum is not quite horizontal, whether it has been remodelled or not. It may also occur when some obstacle prevents the head from sinking into the socket. The results of lateral displacement of the area of contact are the same as those of lack of congruity; the pressure per unit area is too high and bone sclerosis with pain follows.

A faulty position of the stem in the neck can also produce pain, especially coxa valga. This can again be explained by an increase of focal pressure on the acetabulum secondary to medial displacement of the greater trochanter. The same mechanism explains the pain which may develop when the stump of the neck is too short. In our experience, however, the pain 
in such cases of coxa valga or short neck is less than that which results from lack of congruity or lateral displacement of the area of pressure.

Occasionally the stem is too long and must be reduced in length till the end just projects from the subtrochanteric cortex. On the contrary, painful sclerosis of bone may be caused by pressure of the stem against the medullary surface of the cortex when the reamer has failed to perforate it. Finally, we must say that in a few cases of osteoarthritis we do not know the reason why the results are poor.

Thrombophlebitis - There were twenty-one obvious cases $(7 \cdot 3$ per cent), but we must add to that number many slight cases cut short by heparin. We think that venous thrombosis is common and that it may occur to a minor extent in almost every case.

Post-operative dislocation-We have seen thirteen cases, five of which were observed after operation for congenital dislocation and will be mentioned under that heading. Four cases occurred in osteoarthritis; two of these patients had been operated upon previously, and the femoral neck was very short. Dislocation in the remaining four cases followed operation for non-union of fractures of the neck of the femur. In all these cases the dislocation results from a technical mistake: either the neck has been cut too short, the socket is not deep enough, or insufficient care has been taken during the first days after operation. During the last two years we have had no further dislocations. If the dislocation is recognised early it can be reduced by manipulation; otherwise it is better to wait a few weeks before reoperation in order to avoid the risk of infection from the skin. As a rule the end-results are satisfactory.

Mechanical accidents-Fracture of the stem of the prosthesis has not occurred again in five hundred operations since the stem of the prosthesis has been reinforced with a steel core. Undue wear of the surface of the head has occurred in three cases and we are seeking the cause of it.

\section{RESULTS}

Results in osteoarthritis-We refer to all chronic forms of arthritis of the hip, excluding infective polyarthritis. The results are shown in Table III.

TABLE III

Results in 219 Cases of Osteoarthritis

\begin{tabular}{|cccc|}
\hline Bad & Poor & Good & Excellent \\
\hline 17 per cent & 19 per cent & 47 per cent & 17 per cent \\
\hline
\end{tabular}

The amelioration rate-This depends on the age of the patient, the best results being obtained in patients under forty years of age, but the carefully selected patient over seventy years may also obtain a very good result. The average starting rate of our patients was $6 \cdot 8$ and the final rate $13 \cdot 1$. This is a concise way of saying that before operation the typical patient had acute pain so that he could not work, very limited movement so that he could not put his shoe on, and walking restricted to one or two hundred yards; whereas after the operation the pain was slight or intermittent and permitted work, he could put his shoe on, and he could walk a good distance with, or eren without, a stick. When we examined the figures more closely we were surprised to find that the final rate depended on the starting rate only to a small degree; thus the final rate was in most cases between 12 and 14 , whereas the starting rate was commonly between 3 and 11 . This means that we can do much more for a patient with a severely disabled hip than for one retaining good function. It means also that we should as a rule refuse operation to a patient whose starting rate is more than 10 or $\mathbf{1 1}$ because we cannot promise a sufficiently high amelioration rate. The exception comes when the pain is of Grade 1 or 2 , because the relief of acute pain is practically certain.

vol. 34 B, NO. 2, MAY 1952 
Pain-The results from the point of view of relief of pain are shown in Table IV. The final rate for pain has been almost the same whatever the starting rate. To these remarks we must add that night pain, when present, disappeared in $\mathbf{9 3}$ per cent of the cases.

TABLE IV

Relief of Pain ix Osteoarthritis

\begin{tabular}{|c|c|c|c|}
\hline $\begin{array}{c}\text { Number of } \\
\text { cases }\end{array}$ & $\begin{array}{c}\text { Starting } \\
\text { rate }\end{array}$ & $\begin{array}{c}\text { Final } \\
\text { rate }\end{array}$ & $\begin{array}{c}\text { Amelioration } \\
\text { rate }\end{array}$ \\
\hline 73 & 1 & 4.4 & 3.4 \\
67 & 2 & 4.7 & 2.7 \\
73 & 3 & 4.7 & 1.7 \\
6 & 4 & 5.0 & 1.0 \\
\hline
\end{tabular}

Morement-The effect on movement of the hip follows the same lines and can be seen in Table V.

TABLE $V$

INCREASED Range of Movement in Osteoarthritis

\begin{tabular}{|c|ccc|}
\hline $\begin{array}{c}\text { Number of } \\
\text { cases }\end{array}$ & $\begin{array}{c}\text { Starting } \\
\text { rate }\end{array}$ & $\begin{array}{c}\text { Final } \\
\text { rate }\end{array}$ & $\begin{array}{c}\text { Amelioration } \\
\text { rate }\end{array}$ \\
\hline 40 & 1 & $4 \cdot 3$ & $3 \cdot 3$ \\
80 & 2 & $4 \cdot 4$ & $2 \cdot 4$ \\
72 & 3 & $4 \cdot 8$ & $1 \cdot 5$ \\
27 & 4 & $5 \cdot 1$ & $1 \cdot 1$ \\
\hline
\end{tabular}

IValking-The capacity for walking after operation is shown in Table VI. Here the final rate depends to a greater extent on the starting rate. The Table shows that the average

TABLE VI

Capacity for Walking in Osteoarthritis

\begin{tabular}{|cccc|}
\hline $\begin{array}{c}\text { Number of } \\
\text { cases }\end{array}$ & $\begin{array}{c}\text { Starting } \\
\text { rate }\end{array}$ & $\begin{array}{c}\text { Final } \\
\text { rate }\end{array}$ & $\begin{array}{c}\text { Amelioration } \\
\text { rate }\end{array}$ \\
\hline 107 & 1 & $3 \cdot 5$ & $2 \cdot 5$ \\
28 & 2 & $3 \cdot 8$ & $1 \cdot 8$ \\
78 & 3 & 4.2 & 1.2 \\
6 & 4 & $4 \cdot 8$ & 0.8 \\
\hline
\end{tabular}

patient receives a two-point amelioration from the operation. For instance, the patient who could walk only fifty yards can now walk two or three miles with one stick or several hundred yards without. We think that the reason for this finding lies in the power of the hip muscles, upon which depends the patient's ability to walk long distances. The better the muscles before operation the better is the gait afterwards. The best proof of this is the steady improvement in walking which occurs in active patients during the years after the operation. 
Results in fracture of the neck of the femur. Recent fractures-We insert the acrylic head only in special cases. Though our first cases are more than four years old we refrain from extending the method to all cases of fractures of the femoral neck. There are indications both for the standard methods of treatment and for resection-reconstruction. The difficulty is to determine the limitations of our method. For very old people replacement by an acrylic head is sometimes good and safe treatment. In patients aged between fifty and serenty we insert a prosthesis only when we have good reason to fear non-union-for example, when the head is porotic or the fracture is sub-capital. The results have been good. Three patients more than eighty years of age have had a quick and satisfactory result. But the death rate must increase if the method is used too widely and especially in the hands of general surgeons not accustomed to hip surgery.

Non-union of the neck-We have operated on forty-seven patients, ten of whom were completely crippled and unable to walk, and the others able to do so only with two sticks or with crutches. The average final rate has been $13 \cdot 5$. Some special points must be mentioned. The shortness of the stump of the neck compelled us sometimes to put the prosthesis in considerable coxa valga. In two patients we inserted it vertically, so performing "humeralisation" of the femur. In nine cases we had to resect the top of the greater trochanter level with the upper surface of the head. In such cases post-operative dislocation may occur. If the reduction seems unstable it may be necessary to apply a plaster spica for two or three weeks. Osteoporosis of the neck is often severe, but it disappears quickly after operation with the return of active movement.

Results in post-traumatic arthritis-In seven patients the average amelioration rate was 7 ; that is to say good.

Results in old septic arthritis-Out of eleven cases, five were pathological dislocations. For bony ankylosis the operation is the same as for chronic arthritis but the hollowing out of the socket is often more difficult. Results have been good.

Results in congenital dislocation of the hip-Under this heading we have 108 adult patients. Subluxation (thirty-one cases)-These cases are like those of osteoarthritis and nothing more need be said about them except that deepening of the acetabulum is essential. Dislocations (seventy-seven cases)-These cases must be divided into anterior and posterior dislocations. In anterior dislocations (forty-three cases) the femoral head is found below the anterior superior iliac spine next to the ilium; the new socket is shallow and inadequate; the head and the neck are well developed. A moderate lowering of the socket by an inch or a little more is generally possible. The thickness of iliac bone permits good depth for the new socket. The results are good. The average final rate is $13 \cdot 5$ and the amelioration rate $6 \cdot 0$. The limp is usually diminished but the chief benefit for the patient is the relief of pain, which is in fact the chief indication for the operation. Because walking is often fairly good before operation it is not capable of showing great improvement. In posterior dislocations (thirty-four cases) the head is high and posterior in the buttock and lacks any fulcrum against the ilium. In our earliest cases we attempted to make the new joint as near as possible to the normal situation, but by doing so we produced undue tension in blood vessels, nerves and muscles. We have had no vascular accidents but have had two cases of paralysis of the femoral nerve and one of the sciatic. The two former recovered completely but the latter only partly. As for the excessive muscular tension, this leads only to fibrosis with stiffness of the new joint. Now we are less ambitious and try to hollow out the new socket as far forwards as possible under the anterior iliac spine in order to correct the lumbar lordosis; this arthroplasty in fact is more satisfactory than the old transposition of Lance or of Camera. The chief difficulty is the iliac bone, which is often not thick enough to obtain a sufficient depth of socket. We perforate the ilium freely and before reducing the acrylic head pack in all the fragments of bone produced in the deepening process. During the next few weeks the acrylic head moulds these fragments over itself, so making a new acetabulum with

VOL. 34 B, NO. 2, MAY 1952 
intrapelvic protrusion. Instead of this we have sometimes screwed a piece of iliac bone above the head in order to form a shelf. In almost all cases subcutaneous tenotomy of the adductors is necessary.

The post-operative treatment differs from the usual routine. A plaster spica is applied for three or four weeks. After its removal active and passive movements are begun, but weight-bearing is deferred until some time between the sixth and eighth weeks.

Indications for operation in old congenital dislocation-This is a difficult problem. In unilateral cases resection-reconstruction is good, but of course it does not correct all the shortening of the limb. In bilateral cases we must remember that many patients have little pain, that bad radiographic appearances are compatible with quite good function and that limping by itself is not an indication for operation. We reserve operation for those patients who can walk only a very short distance with much pain or fatigue, for those who have a painful lumbar lordosis, and for the asymmetrical cases with an anterior dislocation on one side and a posterior dislocation on the other.

TABLE VII

Results in Seventy-seven Cases of Old Congenital. Dislocation

\begin{tabular}{|l|cc|}
\hline Result & $\begin{array}{c}\text { Anterior dislocations, } \\
\text { forty-three cases }\end{array}$ & $\begin{array}{c}\text { Posterior dislocations, } \\
\text { thirty-four cases }\end{array}$ \\
\hline Bad & 15.3 per cent & $\mathbf{2 8 . 5}$ per cent \\
Fair & $\mathbf{5 3 . 8}$ per cent & $\mathbf{3 5 . 7}$ per cent \\
Good & $\mathbf{3 0 . 7}$ per cent & $\mathbf{3 5 . 7}$ per cent \\
\hline
\end{tabular}

The results have been difficult to assess (Table VII). Movement is often improved and stability even more so. A few months after operation the patient can usually walk farther and more steadily than before, but we must never promise a stylish young woman the disappearance of her limping, because she would be disappointed. This operation does not belong to aesthetic surgery and cannot give such results.

\section{CONGLUSIONS}

At the end of this short study we have to sum up our views about the use of the acrylic prosthesis for arthroplasty of the hip. Some fatalities and a proportion of bad or poor results make this operation one to be undertaken only by surgeons well trained in the surgery of the hip and only on patients who really need it. However, the tolerance of the tissues to acrylic resin and the fixation of the stem in the neck of the femur promise to be lasting. We know that a much longer time is necessary to confirm these general statements, which proceed from an experience of only five years and the study of six hundred cases.

\section{REFERENCE}

Judet, J., and Judet, R. (1950): The Use of an Artificial Femoral Head for Arthroplasty of the Hip Joint: Journal of Bone and Joint Surgery, 32-B, 166. 